\title{
Theoretical modelling of a beam with attached spring-mass-damper system
}

\author{
Syaiful Azmirul Mohd Rozlan ${ }^{1}$, Izzuddin Zaman ${ }^{1,{ }^{*}}$, Bukhari Manshoor ${ }^{1}$, Amir Khalid ${ }^{1}$, \\ Shiau Wei Chan ${ }^{2}$, and Mohd Shahrir Mohd Sani ${ }^{3}$ \\ ${ }^{1}$ Faculty of Mechanical and Manufacturing Engineering, Universiti Tun Hussein Onn Malaysia, \\ 86400 Batu Pahat, Johor, Malaysia \\ ${ }^{2}$ Faculty of Technology Management and Business, Universiti Tun Hussein Onn Malaysia, 86400 \\ Batu Pahat, Johor, Malaysia \\ ${ }^{3}$ Automotive Engineering Centre, Universiti Malaysia Pahang, 26600 Pekan, Pahang, Malaysia
}

\begin{abstract}
Vibrations are always undesirable, wasting energy besides producing noise. In this case, beams which are prominent component in most engineering having no exemption from the vibration effect when imposed by dynamic loading. One of the approach to attenuate vibration of a structure is by having a spring-mass-damper (SMD) system or typically known as vibration neutralizer attached to the vibrating structure. This method is more promising as it does not contribute significant additional energy to the structure. The work presented in this paper describes the frequency response (FRF) of a simply supported beam with an attached SMD system. A mathematical model of a beam was at first developed in the study which was further derived to include the attachment of SMD system. In order to transform the derived equations into a form of graph that can be analysed, Matlab ${ }^{\circledR}$ software was used. The outcome from Matlab ${ }^{\circledR}$ shows that the attachment of SMD onto beam attenuates its vibration significantly. The result also displays a good resemblance FRF when compared with numerical finite element analysis of Ansys ${ }^{\circledR}$. It is expected that the theoretical derivation demonstrated in this paper provide a helpful reference to future researchers who endeavour to find equations of a simply supported beam with an attached SMD system as well as for a vibration control study.
\end{abstract}

\section{Introduction}

A beam is a typically horizontal structural member applied to support vertical loads such as floors, panels, roofs and decks. It is capable of withstanding load primarily by resisting against bending which is caused by the external loads, own weight, span and external reaction when the bending force is induced into the beam [1-4]. There are few support configuration used for beam, for example cantilever, fixed supported and a common one is simply supported [4]. Beam models are usually made to simplify its application such as in structures of automobile frame, bridge, aircraft wings, propeller blades and others

* Corresponding author: izzuddin@uthm.edu.my 
engineering structure. This is because beam models are much easier to be analysed $[5,6]$. Figure 1 shows some of the common examples of beam application.

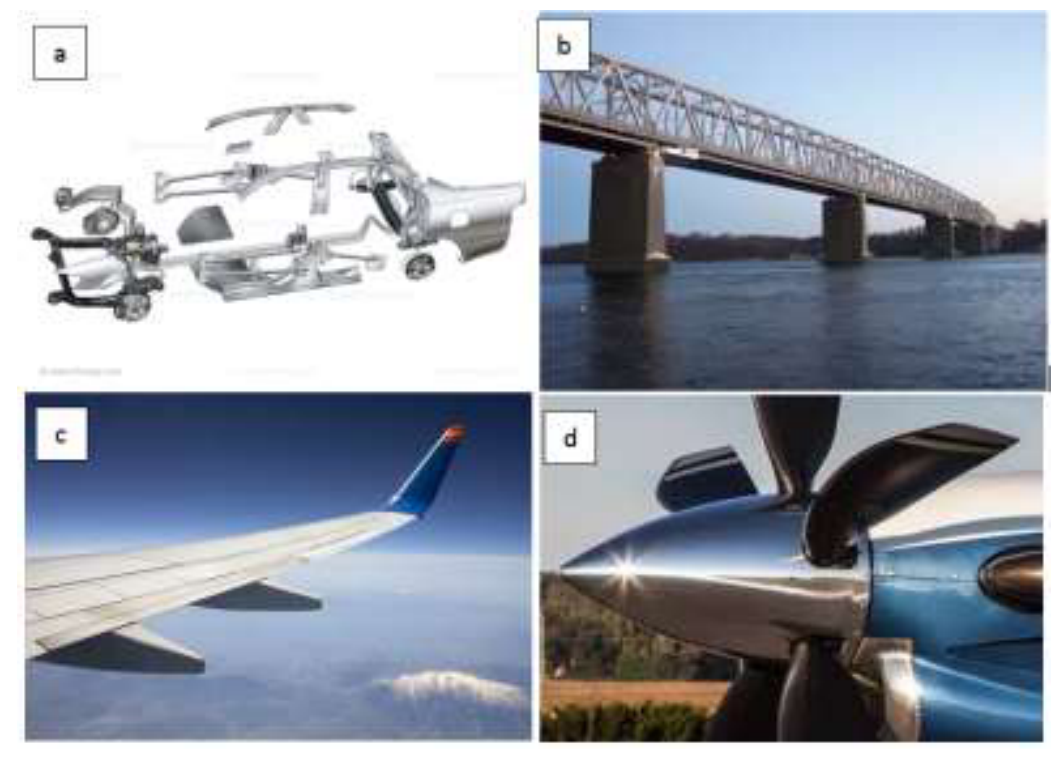

Fig. 1. Potential of beam's applications.

Although beam is a popular structure employed in engineering applications, even it cannot escape from the effects of vibration phenomena when a dynamic load is applied $[7,8]$. With the current trend of using dynamic systems, the exposure of structure to vibration could not be avoided and it would become worse if the structural vibration of beam is not controlled. In other words, vibrations is always not needed because induce uncomfortable noise, lead to excessive deflections and eventually failure of structure [9]. In order to overcome the problem, few methods have been developed for the past 20 years and one of them is by adding vibration neutralizer.

In general, vibration neutralizer consists of spring, mass and damper systems - which is the term used in this study. A vibration neutralizer system has been widely used to suppress or attenuate vibrations in linear, nonlinear vibrating mechanical systems and many structures. The applications of this device can be found particularly in bridges, building structures, aeroplanes, machine tools and others engineering systems [10-16]. A previous study of Hao et al. [14] investigated about tuned vibration neutralizer to suppress of handarm vibration in electric grass trimmer. From the experimental results, it shows that the vibration of the electric grass trimmer with attached neutralizer was reduced almost $95 \%$ along the frequency band. In 2013, Acar \& Yilmaz [15] proposed a new design of the passive dynamic vibration neutralizer made of a string under variable tension. The author used finite element method to verify the natural frequencies of the system and validate data outcome from experiments. A similar study was performed by Rubio et al. [16] who used finite element to investigate the performance of vibration neutralizer attached to a boring bar.

Although it has been proved through the experimental study and finite element analysis that vibration neutralizer can reduce the structural vibration [17-19], none have addressed the theoretical background of vibration absorber attached to the structure in depth. Therefore, this paper strive to present details derivation of a mathematical model which allows the calculation of frequency response function of a simply-supported beam with an attached vibration neutralizer (abbreviated as SMD-spring mass damper system). The 
outcome of this study will provide a helpful reference to future researchers who endeavour to find an equation for a simply-supported beam with attached vibration neutralizer.

\section{Mathematical modelling}

This section describes the derivation of a mathematical model which allows the calculation of frequency response function of a simply supported beam with an attached vibration neutralizer. At first, the mathematical equation for dynamic response of a simply-supported beam is derived, followed by a derivation of SMD system and after that the derivation of a simply-supported beam with attached SMD.

\subsection{Simply-supported beam}

Figure 2 shows the schematic of a simply supported beam. The response of beam $w(x)$ can be determined when beam subjected to vertical load $F(x)$.

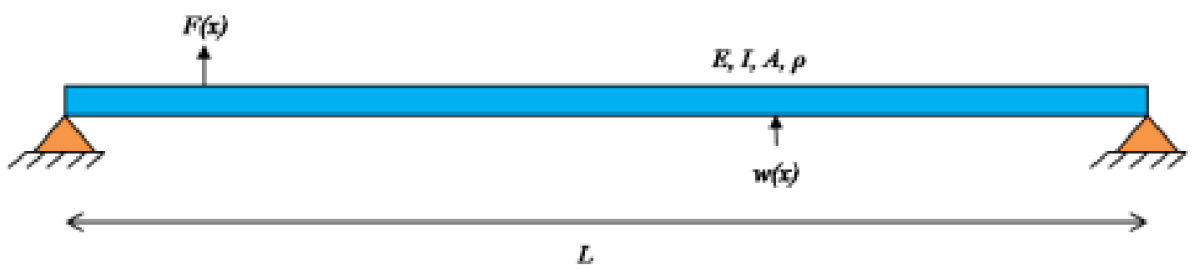

Fig. 2. Schematic of a simply supported beam.

Assuming the Young's modulus $E$, cross sectional area $A$, area moment of inertia $I$ and density $\rho$ are constant along the beam length $L$, the equation of motion for a simplysupported beam can be expressed by [20]:

$$
E I\left(\frac{\partial^{4} w(\mathrm{x}, \mathrm{t})}{\partial x^{4}}\right)+\rho A \frac{\partial^{2} w(\mathrm{x}, \mathrm{t})}{\partial t^{2}}=F(\mathrm{x}, \mathrm{t})
$$

Therefore, the total normal response of beam is given by the summation of superposition of the individual Eigen solutions, or modes given by Eq. (2):

$$
w(x, t)=\sum_{n=1}^{\infty} W_{n} \cdot \psi_{n} e^{j \omega_{n} t}
$$

Where, $W_{n}$ is the modal amplitude, $\psi_{n}$ is the mode shape of a simply supported beam, $\omega_{n}$ is the natural frequency and $n$ is the mode number. The mode shape $\psi_{n}$ of a simply supported beam is given by:

$$
\psi_{n}=\sqrt{2}\left(\frac{n \pi}{L} x\right)
$$

Thus, the natural frequencies of the $n^{\text {th }}$ mode of a simply-supported beam can be calculated from Eq. (4):

$$
\omega_{n}=\left(\frac{n \pi}{L}\right)^{2} \sqrt{\frac{E I}{\rho A}}
$$

Where the area moment of inertia of beam is obtained from Eq. (5):

$$
I=\frac{b h^{3}}{12}
$$


By neglecting the exponential time varying term, the total response of simplysupported beam incorporating the viscous damping $\zeta$ can be simplified as in Eq.(6):

$$
\omega(x, t)=\frac{2 F}{\rho A L} \sum_{n=1}^{\infty} \frac{\left(\sin \left(n \pi x_{1}\right) / L\right) \sin (n \pi x / L)}{\omega_{n}^{2}-\omega^{2}+j 2 \zeta \omega \omega_{m n}}
$$

\subsection{Spring mass damper (SMD) system}

Figure 3 shows the schematic of spring mass damper system. The general equation of motion applied for spring mass damper system is given by Eq. (6) [12]:

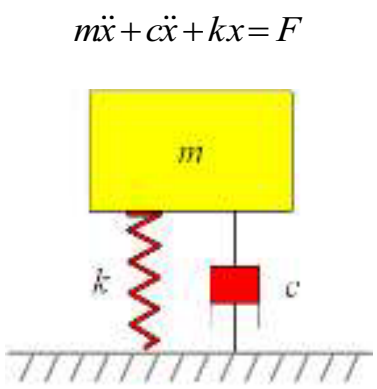

Fig. 3. Schematic of spring mass damper system.

Taking the Laplace transform of a general second order differential equation with initial conditions, the transfer function of the system is:

$$
\frac{x(s)}{F(s)}=\frac{1}{m s^{2}+c s+k}
$$

By applying the following definitions $\zeta=c / 2 \sqrt{k m}$ and $\omega_{n}=\sqrt{k / m}$, Eq. (8) can be further simplified and rewrite as in Eq. (9):

$$
\frac{x(s)}{F(s)}=\frac{1 / m}{s^{2}+2 \zeta \omega_{n} s+\omega_{n}^{2}}
$$

Where, $\omega_{n}$ is the undamped natural frequency and $\zeta$ is the damping ratio.

\subsection{Simply-supported beam with attached SMD system}

Figure 4 shows a simply-supported beam with attached a single degree of freedom SMD system subjected to a harmonic load $F(x)$.

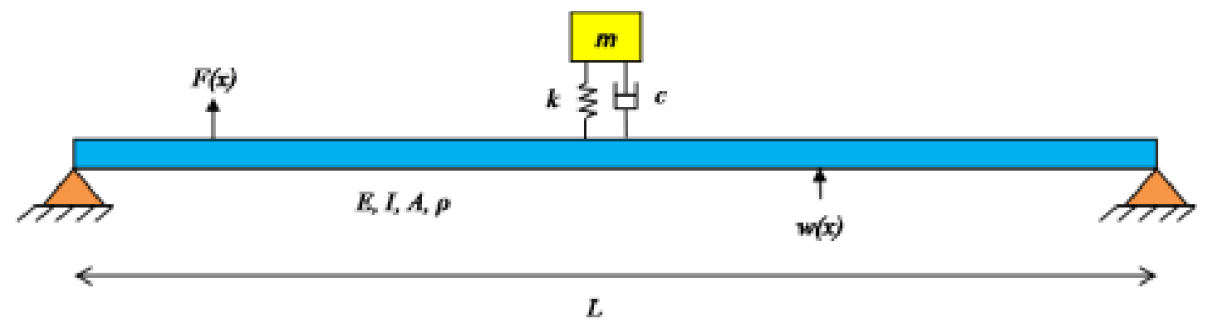

Fig. 4. Schematic of a simply-supported beam attached with a SMD system. 
The equation of motion of a SMD system attached to a simply supported beam is given by Eqs. (10) and (11):

$$
\begin{gathered}
m \dot{y}+c(\dot{y}-\dot{w})+k(y-w)=0 \\
-c(\dot{y}-\dot{w})-k(y-w)=F_{e} e^{s t}
\end{gathered}
$$

Where $y$ is the response of absorber mass, $w$ is the response of a beam at the point of attachment of the spring-damper and $F_{e}$ is a force of spring damper system imparts on the beam.

Let say $y=Y e^{s t}$ and $w=W e^{s t}$, therefore Eqs.(10) and (11) reduce to:

$$
\begin{gathered}
m s^{2} Y+c s Y+k Y-c s W-k W=0 \\
-c s Y-k Y+c s W+k W=F_{e}
\end{gathered}
$$

Putting into matrix form, Eqs. (12) and (13) are simplified as:

$$
\left[\begin{array}{cc}
m s^{2}+c s+k & -(c s+k) \\
-(c s+k) & c s+k
\end{array}\right]=\left[\begin{array}{c}
Y \\
W
\end{array}\right]\left[\begin{array}{c}
0 \\
F_{e}
\end{array}\right]
$$

And solving for $W$ gives:

$$
W=\frac{F_{e}\left(m_{e} s^{2}+c_{e} s+k_{e}\right)}{m_{e} s^{2}\left(c_{e} s+k_{e}\right)}
$$

Therefore, the receptance at a point of attachment of spring-mass damper system on the beam is given by Eq. (16):

$$
\beta_{22}=\frac{m_{e} s^{2}+c_{e} s+k_{e}}{m_{e} s^{2}\left(c_{e} s+k_{e}\right)}
$$

By modifying Eq.(6), the response of the beam at $x_{1}$ with attached spring mass damper system at $x_{2}$ can be calculated using receptance method. The displacement equation for a beam with attached one spring-mass-damper system is simplified as follows:

$$
\omega_{1}(x)=\left[\alpha_{11}-\frac{\alpha_{21}^{2}}{\alpha_{22}+\beta_{22}}\right] F(x)
$$

Where,

$$
\begin{aligned}
& \alpha_{11}=\frac{2}{\rho A L} \sum_{n=1}^{\infty} \frac{\sin ^{2}\left(k_{n} x_{1}\right)}{\omega_{n}^{2}-\omega^{2}+j 2 \zeta \omega \omega_{n}} \\
& \alpha_{21}=\frac{2}{\rho A L} \sum_{n=1}^{\infty} \frac{\sin \left(k_{n} x_{1}\right) \sin \left(k_{n} x_{2}\right)}{\omega_{n}^{2}-\omega^{2}+j 2 \zeta \omega \omega_{n}} \\
& \alpha_{22}=\frac{2}{\rho A L} \sum_{n=1}^{\infty} \frac{\sin ^{2}\left(k_{n} x_{2}\right)}{\omega_{n}^{2}-\omega^{2}+j 2 \zeta \omega \omega_{n}}
\end{aligned}
$$

Where $\omega_{n}$ is the natural frequency of beam, $\zeta$ is the viscous damping of beam, $n$ is the mode number and $k_{n}$ is given by:

$$
k_{n}=\frac{n \pi}{L}
$$

The full solution method involves inverting the mass matrix and solving inhomogeneous Eq.(22) directly.

$$
\left\{-\omega^{2}[M]+j \omega[C]+[K]\right\}\{w\}=\{F\}
$$


Where $[M]$ is structural mass matrix, $[C]$ is structural damping matrix, $[K]$ is structural stiffness matrix, $\{w\}$ is nodal displacement vector and $\{F\}$ is applied load vector.

\section{Results and discussion}

The normalized displacement of a simply-supported beam was plotted against frequency by using Matlab®. The solution method that employed for the harmonic analysis was mode superposition method. This method uses natural frequencies and mode shapes from the modal analysis to characterize the dynamic response of a structure [21,22]. Tables 1 and 2 describe the properties of the beam and SMD that used in the study.

Table 1. Properties and values used in beam analysis.

\begin{tabular}{|l|c|c|c|c|c|c|}
\hline & Length & $\begin{array}{c}\text { Cross Section } \\
\text { Area }\end{array}$ & Height & $\begin{array}{c}\text { Young's } \\
\text { Modulus }\end{array}$ & Density & $\begin{array}{c}\text { Viscous } \\
\text { Damping }\end{array}$ \\
\hline Symbol & $L$ & $A$ & $h$ & $E$ & $\rho$ & $\zeta$ \\
\hline Value & 1.0 & $4.0 \times 10^{-3}$ & 0.02 & 210 & 7850 & 1.0 \\
\hline Units & $\mathrm{m}$ & $\mathrm{m}^{2}$ & $\mathrm{M}$ & $\mathrm{GPa}$ & $\mathrm{kg} / \mathrm{m}^{3}$ & $\%$ \\
\hline
\end{tabular}

Table 2. Properties and values used in SMD.

\begin{tabular}{|l|c|c|c|}
\hline & Mass & Spring & Damping \\
\hline Symbol & $m$ & $k$ & $C$ \\
\hline Value & 1.0 & 1000 & 6.3 \\
\hline Units & $\mathrm{kg}$ & $\mathrm{N} / \mathrm{m}$ & $\mathrm{Ns} / \mathrm{m}$ \\
\hline
\end{tabular}

Figure 5 displays the frequency response function (FRF) and phase angle of the normalized displacement of simply supported beam. The mathematical equation was plotted using Matlab ${ }^{\circledR}$ while numerical model of Ansys ${ }^{\circledR}[23]$ was used to validate this equation. In order to obtain an accurate result, 500 modes were defined in Matlab ${ }^{\circledR}$ for the frequency range of 10 to $1000 \mathrm{~Hz}$. Obviously it can be seen that both theoretical and numerical graphs of displacement and phase show no difference. Table 3 indicates the percentage difference obtained between theoretical and numerical Ansys ${ }^{\circledR}$ are too small and can be negligible. Therefore demonstrate both equation and numerical model developed in the study are accurate.

Table 3. Resonance frequency $(\mathrm{Hz})$ of simply supported beam.

\begin{tabular}{|c|c|c|c|}
\hline Mode $n^{\text {th }}$ & $\begin{array}{c}\text { Theoretical } \\
\text { Matlab }\end{array}$ & Numerical Ansys ${ }^{\circledR}$ & Error (\%) \\
\hline 1 & 47.0 & 46.9 & 0.1 \\
\hline 2 & 187.8 & 187.5 & 0.2 \\
\hline 3 & 421.6 & 421.7 & 0.1 \\
\hline 4 & 749.3 & 749.7 & 0.1 \\
\hline
\end{tabular}



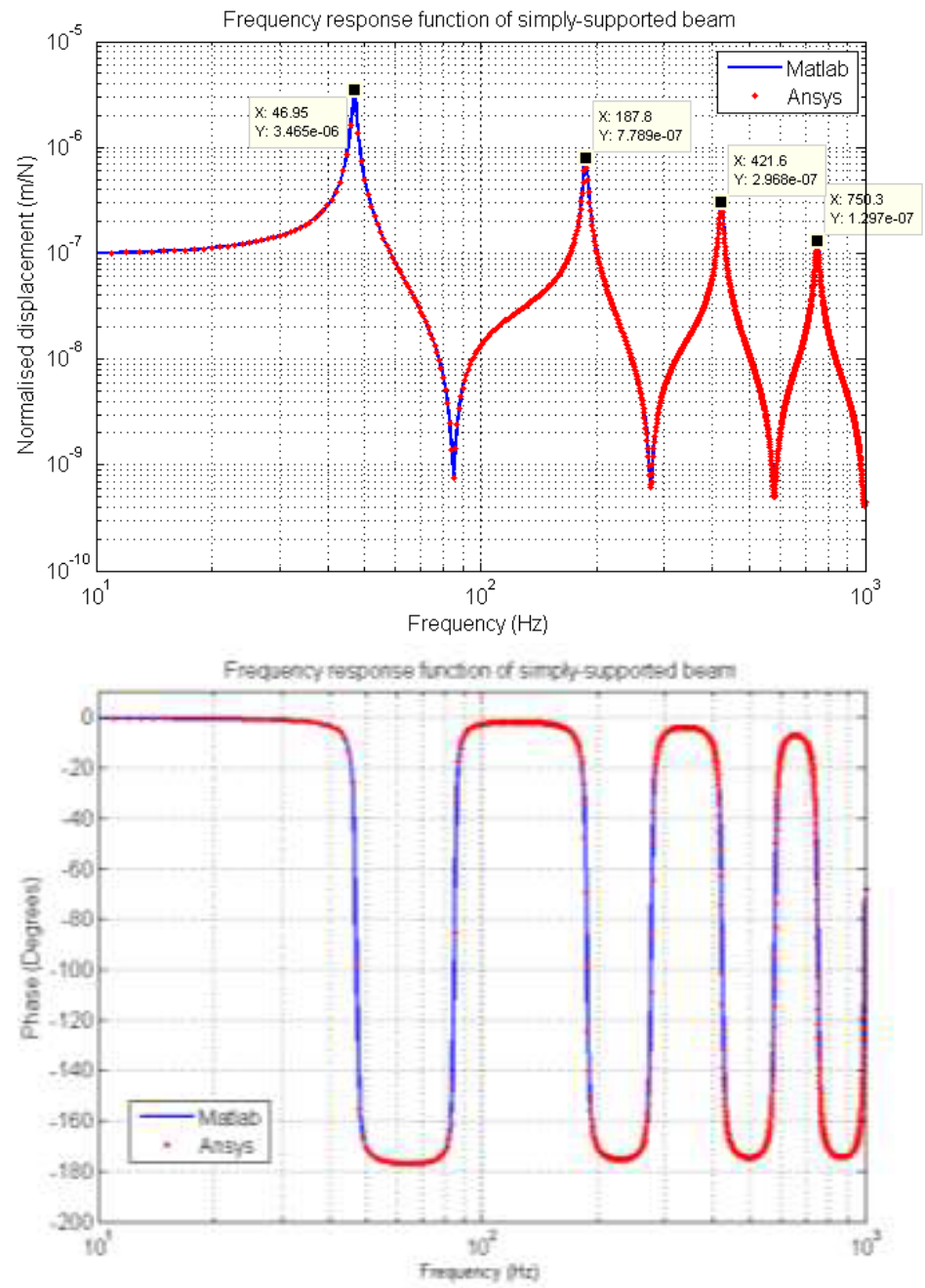

Fig. 5. A comparison of the magnitude and phase of the receptance of a beam.

Figure 6 shows the total displacement and phase of beam with an attached SMD system. Again it shows that the theoretical equation plotted by Matlab ${ }^{\circledR}$ is almost identical with numerical of Ansys ${ }^{\circledR}$. It is found that by adding SMD to a beam has significantly reduce the displacement amplitude about $30 \%$ and this was agreed with our previous findings [1620]. Thus indicates that the derivation of mathematical equation of a simply supported beam with attached SMD was successful. 

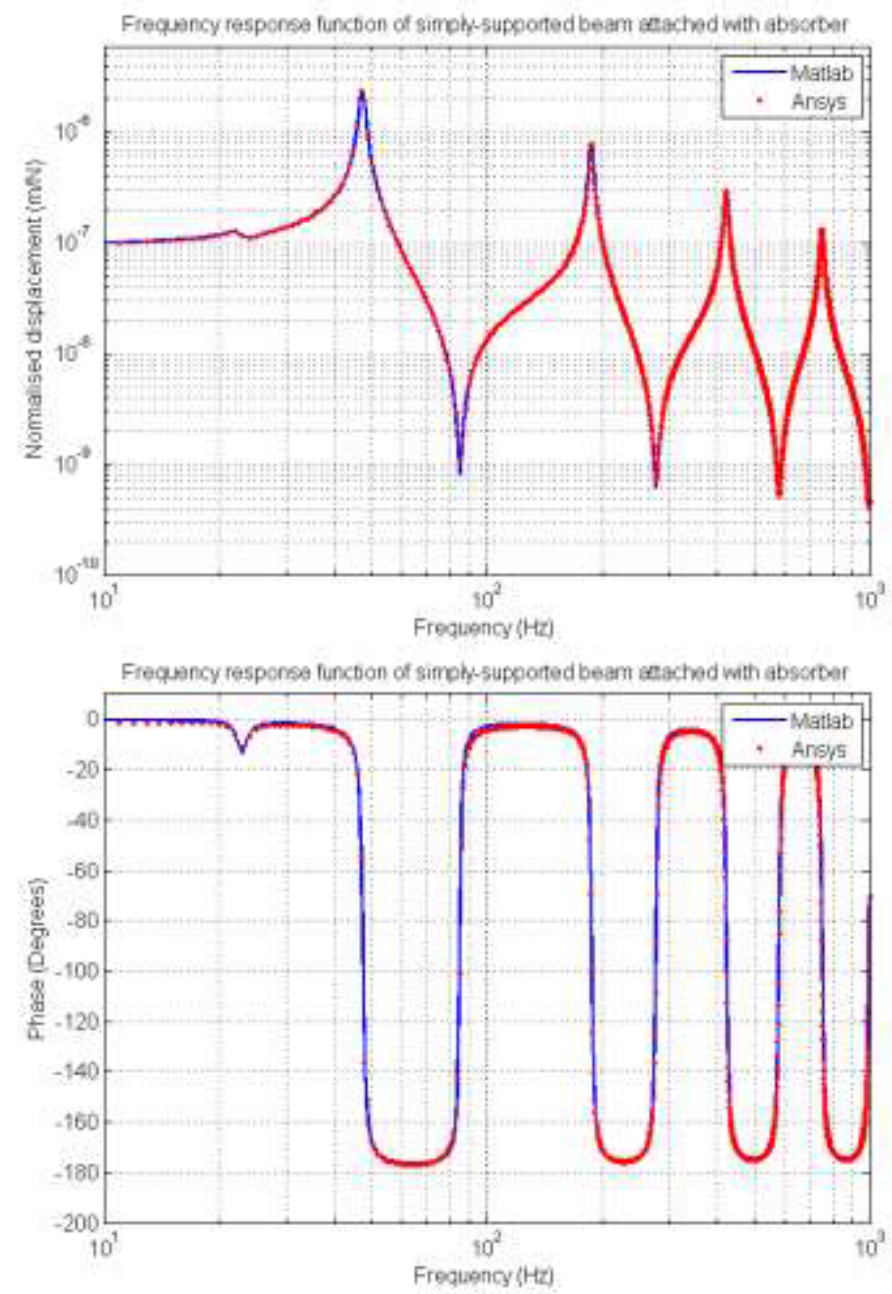

Fig. 6. A comparison of the magnitude and phase of the receptance of simply supported beam with SMD attached.

\section{Conclusions}

In this paper, it was attempted to predict the vibration response of a simply-supported beam with and without an attached SMD system by deriving from the mathematical model. The application software such as Matlab ${ }^{\circledR}$ was used to transform the model into the form of FRF graph. Later, in order to prove this mathematical model, numerical analysis of Ansys ${ }^{\circledR}$ was carried out. Results found that the difference are too small which can be neglected, thus prove the theoretical model prediction.

Special thanks to Research, Innovation, Commercialization and Consultancy Management, Universiti Tun Hussein Onn Malaysia and Ministry of Higher Education Malaysia for the financial support under Fundamental Research Grant Scheme (FRGS) vote 1546 and Incentive Grant Scheme for Publication (IGSP), vote U247. 


\section{References}

1. R. Gonçalves, M. Ritto-Corrêa, D. Camotim, Computational Mechanics 46, 759-781 (2010).

2. G. Piccardo, G. Ranzi, A. Luongo, Mathematics and Mechanics of Solids 19, 900-924 (2014).

3. T. P. Vo, J. Lee, Engineering Structures 30, 1958-1968 (2008).

4. M. Aydogdu, Physica E: Low-dimensional Systems and Nanostructures 41, 1651-1655 (2009).

5. H. Ma, X.-L. Gao, J. Reddy, Journal of the Mechanics and Physics of Solids 56, 33793391 (2008).

6. B. Wang, J. Zhao, S. Zhou, European Journal of Mechanics-A/Solids 29, 591-599 (2010).

7. M. Şimşek, T. Kocatürk, Composite Structures 90, 465-473 (2009).

8. A. E. Alshorbagy, M. Eltaher, F. Mahmoud, Applied Mathematical Modelling 35, 412425 (2011).

9. M. S. Qatu, M. K. Abdelhamid, J. Pang, G. Sheng, International Journal of Vehicle Noise and Vibration 5, 135 (2009).

10. R. I. Wright, M. R. F. Kidner, Journal of Vibration and Control 10, 1221-1237 (2004).

11. I. Zaman, M. M. Salleh, B. Manshoor, A. Khalid, S. Araby, Applied Mechanics and Materials 629, 191-196 (2014).

12. M. J. Brennan, Shock and Vibration 13, 531543 (2006).

13. J. Q. Sun, M. R. Jolly, M. A. Norris, Transactions of the American Society of Mechanical Engineers 117, 234-242 (1995).

14. K. Y. Hao, L. X. Mei, Z. M. Ripin, International journal of industrial ergonomics 41, 494-508 (2011).

15. M. A. Acar, C. Yilmaz, Journal of Sound and Vibration 332, 231-245 (2013).

16. L. Rubio, J. Loya, M. Miguélez, J. Fernández-Sáez, Mechanical Systems and Signal Processing 41, 691-704 (2013).

17. I. Zaman, A. L. M. Tobi, B. Manshoor, A. Khalid, N. A. M. Amin, ARPN Journal of Engineering and Applied Sciences 11, 2308-2313 (2016).

18. H. L. Sun, P. Q. Zhang, X. L. Gong, H. B. Chen, Journal of Sound and Vibration 300, 117-125 (2007).

19. I. Zaman, M. M. Salleh, M. Ismon, B. Manshoor, A. Khalid, M. S. M. Sani, S. Araby, Applied Mechanics and Materials 660, 511-515 (2014).

20. I. Zaman, M. M. Salleh, M. Ismon, B. Manshoor, A. Khalid, M. S. M. Sani, S. Araby, MATEC Web of Conferences 13, 03003 (2014).

21. E. Reynders, Archives of Computational Methods in Engineering 19, 51-124 (2012).

22. I. Zaman, K. A. Kamarudin, M. T. M. Nordin, in International Conference on Construction and Building Technology (ICCBT), Kuala Lumpur, Malaysia (2008).

23. M. M. Salleh, I. Zaman, ARPN Journal of Engineering and Applied Sciences 11, 23362339 (2016). 